Note

\title{
Comparison of beat cloth and entomological net methods for determining faunistic indices of soybean in Rio Grande do Sul, Brazil
}

\author{
Lindolfo Storck ${ }^{1,2 *}$, Claudia Carolina Cabral Antúnez ${ }^{3}$, Jerson Vanderlei Carús Guedes ${ }^{1}$, Alberto Cargnelutti Filho ${ }^{1}$, Jimmy Walter \\ Rasche Alvarez ${ }^{3}$
}

${ }^{1}$ Federal University of Santa Maria, Av. Roraima, 1000 97105-900 - Santa Maria, RS - Brazil.

2Federal University of Technology-Paraná, Via do Conhecimento, km 1 - 85503-390 - Pato Branco, PR Brazil.

${ }^{3}$ National University of Asuncion/Faculty of Agricultural

Sciences - R. 1 Mariscal Estigarribia, km 10,5 - San

Lorenzo - Paraguay.

*Corresponding author <lindolfostorck@gmail.com>

Edited by: Richard V. Glatz

Received April 12, 2015

Accepted December 26, 2015
ABSTRACT: Estimates of diversity indices provide information on distribution, richness and abundance of species within a community. The aim of the current study was to estimate faunistic indices (richness, constancy, dominance and abundance) of the species collected by beat cloth and entomological net sampling methods in different soybean crops and to determine the sample size necessary to estimate faunistic indices. Fauna density from 100 soybeans crops located in nine municipalities in Rio Grande do Sul, Brazil, were evaluated. Thirty points, 20 meters apart from one another, were marked in the crops. At each point, insect pests and natural enemies were collected using the two sampling methods. Faunistic indices, including the average and interval estimates carried out by the resampling method, were calculated for each soybean crop. In the samplings using the beat cloth, richness $>$ dominance $=$ abundance $>$ constancy, and using the entomological nets, richness $>$ dominance $>$ abundance $>$ constancy. All faunistic indices other than dominance were greater when using the beat cloth method than those estimated by the entomological net method. The sample sizes required to estimate richness, constancy, dominance and abundance indices were 38, 78, 47 and more than 300, respectively, with an estimation error of $20 \%$ of the average $(p=0.05)$. Higher values were observed when entomological net was used.

Keywords: Glycine max, resampling, sample size, natural enemies, sampling methods

\section{Introduction}

Brazil is the world's largest soybean producer (Glycine $\max ($ L.) Merrill) and outputting 82 million tons annually. For the 2012/2013 season, in Rio Grande do Sul State, 4.61 million hectares of soybeans were harvested with a production of 12.5 million tons (USDA, 2013).

Throughout the entire soybean cycle, many insects attack the plant and caterpillars and stink bugs are considered the main soybean pests in Rio Grande do Sul State. However, species associated with this crop may vary in terms of composition and population levels, depending on the crop year and location (Haddad et al., 2011). Natural enemies of insect pests can also vary and diversity and insect abundance may be altered by agricultural land use as well as forests and other ecosystems near the crops (Pfiffner and Luka, 2000).

Determining the species in a community is a method to estimate faunal diversity, which can be conducted by species samplings. Different sampling methods are important in sampling insect pests and their natural enemies. For minimal pest management in soybean crops, the most used methods for quantifying the fauna are the beat cloth and the entomological net. Estimates of faunistic indices provide information on distribution, richness and abundance of species within a community. The advantage of such indices is that they generate analyzable data, and by definition, they are devoid of unity, allowing comparisons between communities sampled with a nonstandard method (Wade et al., 2006; Haddad et al., 2011; Martins et al., 2012). Therefore, studies on the diversity of beneficial and pest insects have been performed in different crops (Wade et al., 2006; Stürmer et al., 2012). These studies have used different sampling methods and a variable number of sampling points. In soybean crops, different sampling methods can be important to quantify the faunistic indices.

Due to the need to update information related to minimal pest management and natural enemies in soybean crops, this study aimed to estimate faunistic indices (richness, constancy, dominance and abundance). These indices were developed based on the specimens collected with beat cloths and entomological nets in soybean crops at different altitudes and for different cultivars, while also determining the sample size (number of soybean crops) required for these estimations.

\section{Materials and Methods}

The current study was performed on commercial soybean crops kept with minimal pest management and composed of different soybean cultivars. The fauna was sampled during the soybean reproductive stages $\mathrm{R} 1$ to R6 (Ritchie et al., 1982) 20 or more days after the last pest control. The samplings were performed during three harvests (2010/2011, 2011/2012 and 2012/2013). The soybean crops were located in the quadrant $29^{\circ} 12^{\prime}$ to $30^{\circ} 22^{\prime} \mathrm{S}$ and $53^{\circ} 30^{\prime}$ to $54^{\circ} 20^{\prime} \mathrm{W}$ in the following mu- 
nicipalities of Rio Grande do Sul State, Brazil: São Sepé, Formigueiro, Restinga Seca, Itaara, Júlio de Castilhos, São Pedro do Sul, Dilermando de Aguiar, Santa Maria and São Gabriel.

In each soybean crop (100 crops in total), a 30equi quadrant determining the species in a community that comprised the species in a community distant points (three rows of 10 points each, $20 \mathrm{~m}$ apart) was marked. The altitude $(55-490 \mathrm{~m})$ of each of these quadrants (for each soybean crop) was recorded. In each of the 30 points per quadrant, the fauna was sampled using the two sampling methods (entomological net and beat cloth). The beat cloth was used first on the right side of the marked point and the entomological net was used on the left. Because the sampling methods were applied 1.5 meters apart, the results should not have produced bias. The entomological net consisted of a wooden handle $(1.0 \mathrm{~m})$ and net $(0.35 \mathrm{~cm}$ diameter $)$, while the beat cloth consisted of a white cloth (1.0 m long and $1.0 \mathrm{~m}$ wide) with edges inserted into a wooden handle (Drees and Rice, 1985).

Samplings using the entomological net were performed by passing it five times over two rows of plants, forming an "open eight" design. The beat cloth was placed at the bottom of a soybean row and another row was forcefully shaken for insect pests and beneficial insects to be deposited onto the cloth.

The fauna collected at each point for each crop was identified in the field when possible. The unidentified species were placed in containers properly labeled according to each sampling method and transported to the laboratory for identification. For genus and species identification of specimens of the subfamily Plusiinae, mandibles and spinnerets of caterpillars were observed with the aid of a stereoscope. The data were entered into electronic spreadsheets that contained quadrant information (altitude and cultivar) as well as the points, the sampling method and the frequency of the species sampled.

Faunistic indices (abundance, constancy, dominance and richness) were calculated for each of the 100 soybean crops using the data recorded for each sampling method.

Abundance $(A$, in \%) refers to the average number of individuals per point (Silveira Neto et al., 1976) and was calculated using the following formula:

$$
A=100 \sum_{k=1}^{N s} N I_{k} / 30 N s, \text { where }
$$

$N I_{k}=$ the number of individuals of species $\mathrm{k}$ observed in the 30 points; and

$N s=$ the total number of species observed in the 100 soybean crops.

Constancy $(\mathrm{C}$, in \%) refers to the percentage of specimens of a species in relation to the total number of specimens (Silveira Neto et al., 1976), calculated using the following formula:

$C=100 \sum_{k=1}^{N s} N P_{k} / 30 N s$, where
$N P_{k}=$ the number of points in which the species $\mathrm{k}$ is present (in any amount).

Dominance $(\mathrm{D}$, in $\%)$ is equal to the proportion of the total number of points that corresponds to the dominant species (Silveira Neto et al., 1976). The species whose frequency exceeded the limit calculated by the following formula was considered the dominant species:

$D=100 \sum_{k=1}^{N s} D_{k} / 30 N s$, where

$\mathrm{Dk}=1$ if $\left(N I_{k} / \sum_{k=1}^{N s} N I_{k}\right)>1 / N s$; otherwise, $\mathrm{Dk}=0$.

Richness $(R$, in $\%)$ is the average number of species observed in a soybean crop in relation to the total number of species observed in all soybean crops (Silveira Neto et al., 1976):

$$
\begin{aligned}
& R=100 \sum_{k=1}^{N s} R_{k} / N s, \text { where } \\
& R_{k}=1 \text { if } N I_{k}>0 ; \text { otherwise, } R_{k}=0 .
\end{aligned}
$$

The minimum and maximum values, the average and the coefficient of variation (CV) were calculated using the faunistic indices values. The interval estimate $(1-p=0.95)$ was obtained by the bootstrap method with 2,000 resamplings. Therefore, all 100 values were resampled 2,000 times with replacements and the average of each resampling was calculated. The 2,000 averages obtained with resamplings were sorted to identify 0.025 quantile as the lower limit (LL) and 0.975 quantile as the superior limit (SL). LL and SL values correspond to estimates by the bootstrap confidence interval $\left(\mathrm{CI}_{\mathrm{B}}\right)$ with an error rate of $p=0.05$.

For each of the faunistic indices and sampling methods, the sample size (number of quadrants) necessary to estimate the faunistic indices based on an estimation error of $20 \%$ of the average with a $5 \%$ error probability was estimated using the bootstrap resampling method (Efron, 1979) and applied as indicated in Storck et al. (2012). In this procedure, 2,000 resamplings with replacements were repeated for different resamplings sizes or numbers of quadrants $(\mathrm{k}=3,4, \ldots, 300)$. For each $\mathrm{k}$ value, 2,000 averages obtained with 2,000 resamplings of size $\mathrm{k}$ were sorted to identify 0.025 quantile as LL (k) or 0.975 quantile as the SL (k). The limits LL $(\mathrm{k})$ and SL $(\mathrm{k})$ are interval estimates with an error rate equal to 0.05 with $\mathrm{N}=\mathrm{k}$. The $\mathrm{k}$ value that corresponds to the amplitude size of the previously accepted error (amplitude $(\mathrm{k})=\mathrm{SL}(\mathrm{k})-\mathrm{LL}(\mathrm{k})$ ) is the optimal sample size (number of quadrants). Features available in the R software were used to calculate these statistics.

The Pearson correlation coefficients were estimated among the faunistic indices for each sampling method and bewteen methods for each index. Averages of the altitude and cultivar classes were compared by the bootstrap t-test ( $p=0.05 ; 5,000$ resampling) using the software BioEstat (Ayres et al., 2012). 


\section{Results and Discussion}

\section{Fauna in the soybean crop}

The total numbers of specimens collected in the 100 soybean crops in the three growing seasons were 18,717 and 9,423 insects using the beat cloth and entomological net methods, respectively. Among the 36 species collected, there were species from the orders Lepidoptera, Hemiptera, Coleoptera, Hymenoptera, Thysanoptera, Mantodea, Neuroptera and Dermaptera, as well as specimens of the Arachnida class and the Araneae order.

Of the total number of insects collected with the beat cloth method $(18,717), 16,478$ specimens (88 \%) corresponded to pests and 2,239 (12\%) corresponded to natural enemies. However, in the samplings using the entomological net method, $82 \%(7,710)$ were pests and $18 \%$ were natural enemies. Thus, the entomological net method captured a higher number of natural enemies (in percentage) than did the beat cloth method, and this result might be explained by the higher mobility of certain insects, especially flying insect predators. Because they have to locate and chase prey, flying insect predators are more agile and capable of avoiding capture with the beat cloth method. Therefore, it can be inferred that the entomological net method is the most suitable method to capture natural enemies in soybean crops, especially predators.

Within the order Lepidoptera, the highest number of collected pests belonged to species Chrysodeixis (Pseudoplusia) includens (Walker, 1857) (Lepidoptera: Plusiinae), Anticarsia gemmatalis (Hueb., 1818) (Lepidoptera: Erebidaedae) and Rachiplusia nu (Guen., 1852) (Lepidoptera: Plusiinae), which collectively corresponded to $62 \%$ and $34 \%$ of the total number of insects collected by beat cloth and entomological net, respectively. The most abundant pests of the order Hemiptera were the species Dichelops sp. (Fabr., 1794), Piezodorus guildinii (Westwood, 1837) and Euchistus heros (Fabr., 1794) (all Hemiptera: Pentatomidae), representing collectively $17 \%$ and $10 \%$ of the total number of insects collected by beat cloth and entomological net, respectively. Other collected species were Nezara viridula (Linnaeus 1758) and Edessa meditabunda (Fabricius, 1794) (Hemiptera: Pentatomidae) as well as representatives of the family Lygaeidae.

Specimens of Cerotoma sp. and Diabrotica speciosa (Germar, 1824) (Coleoptera: Chrysomelidae), Lagria villosa (Fabricius, 1783) (Coleoptera: Lagriidae) and Aracanthus mourei (Coleoptera: Curculionidae) were also collected. Coleopteran pests represented $9 \%$ and $2 \%$ of the total collections using beat cloth and entomological net, respectively.

Hemiptera of the family Cicadellidae and Thysanoptera of the family Thripidae were collected, representing $0.4 \%$ and $0.1 \%$, respectively, of the total number of insects collected by beat cloth; however, they represented $14 \%$ and $5 \%$, respectively, of the insects collected by entomological net. The entomological net method collected a higher percentage of pests because they are fast and able to escape from counts when beat cloth is used. Based on the average density of pests, beat cloth is more efficient to collect pests; however, certain pests are collected in greater numbers using entomological net, indicating that the entomological net methods may complement pest samplings. Comparing the collecting capacity of three types of beat cloths, one study showed that the vertical beat cloth was the most efficient to collect caterpillars and stink bugs (Stürmer et al., 2012).

Regarding natural enemies, species Cycloneda sanguinea (Linnaeus, 1763), Hippodamia convergens (GuérinMéneville, 1842), Harmonia axyridis (Pallas, 1773), Eriopis connexa (German, 1824) and Coleomegilla maculata (De Geer, 1775) (Coleptera: Coccinellidae) were collected. Predators Zelus sp. (Hemiptera: Reduviidae), Nabis sp. (Hemiptera: Nabidae), Geocoris sp. (Hemiptera: Lygaeidae) and Orius sp. (Hemiptera: Anthocoridae) were also collected.

Representatives of orders Mantodea (Family: Mantidae), Neuroptera (Family: Chrysopidae) and Doru sp. (Dermaptera: Forficulidae) were also collected. Among the Hymenoptera, bees (Aphidae) and ants (Formicidae) were collected. Spiders were also collected. Predator species (C. sanguinea, H. convergens, E. connexa, Zelus sp., Nabis sp., Geocoris sp., Orius sp., Doru sp.) collected have also been reported in other states of Brazil. Based on these results, species of predators were stable across the region studied; therefore, the crop factor is more relevant than variations in location.

\section{Faunistic indices}

The average, minimum and maximum values, as well as the CV, LL and SL of the bootstrap confidence interval and the sample size (number of quadrants) required to estimate faunistic indices based on an estimation error of $20 \%$ of the average (Table 1). The dominance index estimated by beat cloth $(15 \%)$ did not differ from that estimated by entomological net $(15 \%)$ according to the bootstrap resampling test $(p=$ 0.05), which was determined by a comparison of LL and SL limits for beat cloth with limits for entomological net. When the confidence interval (LL to SL) of the methods overlapped, the methods were considered equivalent. Thus, faunistic indices were hogher for richness, constancy and abundance estimated in beat cloth than in entomological net. Samplings of beat cloth and entomological net showed the following trends: $\mathrm{R}>\mathrm{D}, \mathrm{D}=\mathrm{A}, \mathrm{A}>\mathrm{C}$ and $\mathrm{R}>\mathrm{D}, \mathrm{D}>\mathrm{A}$, $A>C$, respectively. Measurements of diversity (pests and natural enemies) frequently appear as indicators of an ecosystem health, with high richness values indicating higher diversity and lower pest management needs. However, the increased abundance values of a few species indicate less diversity; therefore, greater 
Table 1 - Richness, constancy, dominance and abundance of species sampled with the beat cloth and entomological net methods in 100 soybean crops. Minimum and maximum values, average, lower limit (LL) and superior limit (SL) of the bootstrap confidence interval (1- $p=0.95)$ and sample size for a semi-amplitude of the bootstrap confidence interval $(1-p=0.95)$ equal to $20 \%$ of the average $\left(n_{0}\right)$.

\begin{tabular}{|c|c|c|c|c|}
\hline \multirow{2}{*}{ Statistics } & \multicolumn{2}{|c|}{ Richness } & \multicolumn{2}{|c|}{ Constancy } \\
\hline & Cloth & Net & Cloth & Net \\
\hline Minimum value & 8.11 & 2.86 & 0.45 & 0.29 \\
\hline Average & 30.35 & 25.26 & 6.22 & 4.42 \\
\hline Maximum Value & 51.35 & 48.57 & 13.06 & 13.43 \\
\hline CV (\%) & 31.1 & 37.5 & 45.6 & 59.4 \\
\hline LL & 28.46 & 23.49 & 5.64 & 3.91 \\
\hline SL & 32.19 & 27.11 & 6.78 & 4.96 \\
\hline \multirow[t]{2}{*}{$\mathrm{n}_{0}$} & 38 & 54 & 78 & 131 \\
\hline & \multicolumn{2}{|c|}{ Dominance } & \multicolumn{2}{|c|}{ Abundance } \\
\hline Minimum value & 2.70 & 2.86 & 0.63 & 0.29 \\
\hline Average & 15.14 & 15.46 & 16.86 & 8.98 \\
\hline Maximum Value & 29.73 & 37.14 & 76.40 & 44.19 \\
\hline CV (\%) & 35.5 & 38.4 & 91.1 & 91.0 \\
\hline LL & 14.05 & 14.31 & 13.97 & 7.45 \\
\hline$S L$ & 16.22 & 16.69 & 19.94 & 10.66 \\
\hline$n_{0}$ & 47 & 52 & $>300$ & $>300$ \\
\hline
\end{tabular}

dominance indices indicate lower diversity (Bomfim et al., 2007). The use of beat cloth resulted in greater capture of pest species. However, entomological net sampled a greater number of natural enemies, especially coccinellids and chrysopids, as well as certain pests (beetles, leafhoppers and thrips), which can be explained by the movement of insects. Therefore, faster insects escape more easily from beat cloth than from entomological net. However, less mobile species, such as caterpillars and certain beetles, were collected in larger numbers by beat cloth; therefore, the sampling method result is influenced by species and habits of the insect.

The sampling methods used in the current study resulted in the collection of different species in the different samples. For example, entomological net collected more thrips and leafhoppers than beat cloth did and the number of stink bugs and species collected by the different sampling methods was also different. This result indicates that the two methods have advantages with different species of pests or natural enemies. The relationship between the sampling method and the target insect must be acknowledged to improve method accuracy and represent populations that occur in the soybean crop. The fact that different sampling methods collect different species shows that most species are not collected by a single method. Therefore, the two sampling methods included here should be considered for soybean and more than one sampling method should be considered in studies to determine faunistic indices.

\section{Sample size}

For an estimation error of $20 \%$ of the average with a $5 \%$ error probability, the sample size (number of quadrants) (Table 1) required to estimate the richness index was 38 quadrants (soybean crops) using beat cloth, which means that 38 sampling sites or crops would be necessary for an accurate value. This value, which is lower than the number of quadrants (100 soybean crops) sampled in the current study, decreases with an increasing estimation error. For an estimation error of $20 \%$, the sample size necessary to estimate faunistic indices for richness, constancy and dominance using entomological net would be $42 \%, 68 \%$ and $11 \%$, respectively, higher than the sample sizes estimated for beat cloth. Regarding faunistic indices for abundance, the sample size is greater than 296 quadrants for both sampling methods when the same $(20 \%)$ estimation error is applied. To estimate indices for richness, constancy and dominance, the researcher may apply a larger estimation error if the variability pattern of faunistic indices values in different soybean crops are maintained. Perner (2003) studied the sample size necessary to achieve accurate results in agricultural ecosystems when determining faunistic indices of arthropods and reported that to calculate richness indices, a larger number of samples were necessary. The author also concluded that the sample size varies considerably within sampling sites, sampling years and taxonomic groups.

\section{Pest management}

Integrated pest management (IPM) of the soybean crop recommends weekly surveys on populations of pests and natural enemies as a pre-requisite for pest control decisions, thus, the results of the current study will be useful for IPM programs. However, the recent occurrence of Helicoverpa armigera has led technicians to advocate monitoring soybean caterpillars up to twice weekly, which increases costs; therefore, a safe and accurate method for acquiring the required sample size is desirable.

The average values of faunistic indices by cultivar are shown in Table 2. In the soybean crop of BMX Potencia RR cultivar, which was the most frequent cultivar (26\%) among the crops studied, averages of indices for richness, constancy, dominance and abundance were 30 $\%, 6 \%, 13 \%$ and $20 \%$, respectively, using beat cloth method and $23 \%, 4 \%, 14 \%$ and $8 \%$, respectively, using entomological net. No differences were observed among the cultivars for faunistic indices, possibly due the small number of soybean crops for most cultivars. Therefore, it can be inferred that the cultivars do not affect the numerical balance of species that inhabit soybean crops, which may indicate that the same pest management can be used for all soybean crops.

Faunistic indices (Table 3) for constancy and abundance from beat cloth samplings and for richness and dominance from entomological net samplings were higher $(p<0.05)$ at lower altitudes (below $150 \mathrm{~m}$ ) than at higher altitudes (above $150 \mathrm{~m})$. Therefore, it can be in- 
Table 2 - Number of soybean crops (N) per cultivar. Richness (R), constancy (C), dominance (D) and abundance (A) average values of samplings using the beat cloth and entomological net methods.

\begin{tabular}{|c|c|c|c|c|c|c|c|c|c|}
\hline \multirow{2}{*}{ Cultivar } & \multirow[b]{2}{*}{$\mathrm{N}$} & \multicolumn{4}{|c|}{ Beat cloth } & \multicolumn{4}{|c|}{ Entomological net } \\
\hline & & $\mathrm{R}$ & C & $\mathrm{D}$ & $A$ & $\mathrm{R}$ & $\mathrm{C}$ & $\mathrm{D}$ & $A$ \\
\hline BMXPotencia RR & 26 & $29.63^{\text {ns }}$ & 6.54 & 13.20 & 19.91 & 22.75 & 3.95 & 13.96 & 7.70 \\
\hline Nidera 5909 & 20 & 29.73 & 5.89 & 13.65 & 15.76 & 26.57 & 4.74 & 16.14 & 9.39 \\
\hline A8000 & 10 & 25.14 & 4.69 & 14.87 & 14.17 & 23.43 & 4.11 & 13.14 & 9.62 \\
\hline Codetec 231 & 9 & 30.93 & 7.35 & 14.72 & 21.57 & 23.81 & 3.77 & 17.46 & 7.70 \\
\hline Tijereta LT 2162 & 6 & 30.17 & 4.93 & 13.06 & 11.05 & 21.43 & 3.59 & 12.86 & 6.43 \\
\hline BMX Turbo RR & 6 & 36.04 & 6.56 & 21.62 & 14.26 & 28.57 & 2.78 & 22.86 & 3.73 \\
\hline Codetec 5909 & 5 & 28.65 & 6.83 & 16.76 & 18.07 & 30.29 & 5.87 & 15.43 & 12.55 \\
\hline Nidera 6411 & 5 & 34.59 & 6.65 & 17.30 & 12.88 & 28.57 & 6.46 & 14.86 & 15.28 \\
\hline Apolo & 4 & 39.19 & 7.79 & 16.89 & 28.56 & 30.00 & 6.45 & 17.86 & 12.26 \\
\hline Others & 9 & 30.03 & 5.95 & 18.92 & 10.73 & 26.67 & 4.91 & 14.92 & 10.61 \\
\hline Average & 100 & 30.35 & 6.22 & 15.14 & 16.86 & 25.26 & 4.42 & 15.46 & 8.98 \\
\hline
\end{tabular}

Table 3 - Number of soybean crop (N) per altitude class. Richness (R), constancy (C), dominance (D) and abundance (A) average values of samplings using the beat cloth and entomological net methods.

\begin{tabular}{|c|c|c|c|c|c|c|c|c|c|}
\hline \multirow{2}{*}{ Altitude } & \multirow[b]{2}{*}{ N } & \multicolumn{4}{|c|}{ Beat cloth } & \multicolumn{4}{|c|}{ Entomological net } \\
\hline & & R & C & $\mathrm{D}$ & $A$ & $\mathrm{R}$ & $C$ & $\mathrm{D}$ & A \\
\hline$<150 m$ & 61 & $31.46 a^{*}$ & $6.86 \mathrm{a}$ & $15.11 \mathrm{a}$ & $19.96 \mathrm{a}$ & $27.03 \mathrm{a}$ & $4.78 \mathrm{a}$ & $16.58 \mathrm{a}$ & $9.68 \mathrm{a}$ \\
\hline$>150 \mathrm{~m}$ & 39 & $28.62 \mathrm{a}$ & $5.23 b$ & $15.18 \mathrm{a}$ & $12.02 \mathrm{~b}$ & $22.49 b$ & $3.86 \mathrm{a}$ & $13.70 \mathrm{~b}$ & $7.89 \mathrm{a}$ \\
\hline Average & 100 & 30.35 & 6.22 & 15.14 & 16.86 & 25.26 & 4.42 & 15.46 & 8.98 \\
\hline
\end{tabular}

*Altitudes with averages not followed by the same letter differ by the bootstrap $t$ test $(5,000$ re-samplings, $p<0.05)$.

ferred that constancy and abundance (indices that measure the number of specimens by point) are different in terms of altitude when beat cloth is used because this method is better to measure the number of specimens per point. Richness and dominance (indices that measure the number of species per point) are different in terms of altitude, when entomological net is used, because this method captures a larger number of species. Regarding different environments, no-till areas and large forest fragments have higher diversity of Carabidae and Staphylinidae species compared with areas under conventional tillage (Martins et al., 2012); thus, the environment can influence faunistic indices.

\section{Correlations}

For the 100 soybean crops, the Pearson correlation coefficients between the faunistic indices were positive $(p<0.05)$ in both methods (Table 4). The correlation between dominance and abundance indices was negative, but very low $(\mathrm{r}=-0.18, p<0.05)$. The highest positive correlation was observed between constancy and abundance indices $(\mathrm{r}=0.87, p<0.05)$ in the samplings using entomological net. This result indicates that these two indices have similar sensitivity, although the magnitude of the abundance index was higher than that of the constancy index when relative interval estimates were compared (Table 1). Similarly, correlation between abundance and constancy indices $(\mathrm{r}=0.78, p<0.05)$ from beat cloth sampling indicates that greater abundance indices mean greater constancy indices.
Table 4 - Pearson correlation coefficients of the faunistic indices estimates for richness (R), constancy (C), dominance (D) and abundance (A) obtained in samplings using the entomological net and beat cloth methods in 100 soybean crops.

\begin{tabular}{|c|c|c|c|c|c|c|c|c|c|}
\hline \multirow{2}{*}{\multicolumn{2}{|c|}{ Sampling }} & \multicolumn{4}{|c|}{ Entomological net } & \multicolumn{4}{|c|}{ Beat cloth } \\
\hline & & $\mathrm{R}$ & $C$ & $\mathrm{D}$ & A & $\mathrm{R}$ & $\mathrm{C}$ & $\mathrm{D}$ & A \\
\hline \multirow{4}{*}{ 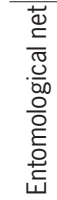 } & $\mathrm{R}$ & 1 & $0.73^{*}$ & $0.46^{*}$ & $0.59^{*}$ & $0.51^{*}$ & - & - & - \\
\hline & C & $0.73^{*}$ & 1 & 0.04 & $0.87^{\star}$ & - & $0.49^{*}$ & - & - \\
\hline & D & $0.46^{*}$ & 0.04 & 1 & $-0.18^{*}$ & - & - & $0.29 *$ & - \\
\hline & A & $0.59^{*}$ & $0.87^{*}$ & $-0.18^{*}$ & 1 & - & - & - & $0.36^{*}$ \\
\hline \multirow{4}{*}{ 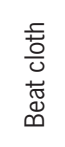 } & $\mathrm{R}$ & & & & & 1 & $0.78^{*}$ & $0.25^{*}$ & $0.45^{*}$ \\
\hline & C & & & & & $0.78^{*}$ & 1 & 0.01 & $0.78^{*}$ \\
\hline & D & & & & & $0.25^{*}$ & 0.01 & 1 & -0.34 \\
\hline & A & & & & & $0.45^{*}$ & $0.78^{*}$ & $-0.34^{*}$ & 1 \\
\hline
\end{tabular}

*Significance determined by t-test $(p<0.05)$.

Correlation between the sampling methods (beat cloth and entomological net) for the same indices (Table 4) resulted in positive estimates for richness $(\mathrm{r}=0.51$, $p<0.05)$, constancy $(\mathrm{r}=0.49, p<0.05)$, dominance $(\mathrm{r}=0.29, p<0.05)$ and abundance $(\mathrm{r}=0.36, p<0.05)$. For the same faunistic indices, correlation between the sampling methods is significant, but weak because of differences in the method discernment. Beat cloth is adequate to capture more specimens per point (best for estimating $\mathrm{C}$ and $\mathrm{A}$ indices), while entomological net is suitable to capture more species per point (best for estimating $\mathrm{R}$ and $\mathrm{D}$ indices). 
Therefore, entomological net was the most suitable sampling method for predators of soybean pests, whereas beat cloth was suitable for sampling soybean pests. The sample size (number of soybean crops) varied depending on faunistic indices and sampling methods. There are differences between the sampling methods. Beat cloth sampling is adequate for capturing more specimens per point (best for estimating $\mathrm{C}$ and A indices), whereas entomological net sampling is adequate for captureing more species per point (best for estimating $\mathrm{R}$ and $\mathrm{D}$ indices). The cultivar does not affect estimates of faunistic indices; however, altitude does have an effect and faunistic indices of richness, constancy and abundance estimated in beat cloth were higher than in entomological net.

\section{Acknowledgements}

The authors are grateful to the Brazilian National Council for Scientific and Technological Development (CNPq) (fellowship for research productivity) and to the Coordination for the Improvement of Higher Level Personnel (CAPES).

\section{References}

Ayres, M.; Ayres Jr., M.; Ayres, D.L.; Santos, A.A.S. 2012. BioEstat - Statistical applications in biomedical sciences areas. Available at: http://www.mamiraua.org.br/pt-br/downloads/programas/ bioestat-versao-53/ [Accessed Apr. 11, 2015]

Bomfim, D.; Uchôa-Fernandes, M.; Bragança, M. 2007. Biodiversity of fruit flies (Diptera, Tephritoidea) in native forests and orchards in two counties of the State of Tocantins, Brazil. Revista Brasileira de Entomologia 51: 217-233 (in Portuguese, with abstract in English).

Drees, B.M.; Rice, M.E. 1985. The vertical beat sheet: a new device for sampling soybean insects. Journal of Economic Entomology 78: 1507-1510.

Efron, B. 1979. Bootstrap method: another look at the jackknife. The Annals of Statistics 7: 1-26.
Haddad, G.Q.; Cividanes, F.J.; Mantins, I.C.F. 2011. Species diversity of Myrmecofauna and Araneofauna associated with agroecosystem and forest fragments and their interaction with Carabidae and Staphylinidae (Coleoptera). Florida Entomologist 94: 500-509.

Martins, I.C.F.; Cividanes, F.J.; Ide, S.; Haddad, G.Q. 2012. Diversity and habitat preferences of Carabidae and Staphylinidae (Coleoptera) in two agroecosystems. Bragantia 71: 471-480.

Perner, J. 2003. Sample size and quality of indication: a case study using ground-dwelling arthropods as indicators in agricultural ecosystems. Agriculture, Ecosystem \& Environment 98: 125132.

Pfiffner, L.; Luka, H. 2000. Overwintering of arthropods in soils of arable fields and adjacente semi-natural habitats. Agriculture, Ecosystem \& Environment 78: 215-222.

Ritchie, S.W.; Hanway, J.J.; Thompson, H.E. 1982. How a Soybean Plant Develops. Iowa State University, Cooperative Extension Service, Ames, IA, USA. (Special Report, 371 53).

Silveira Neto, S.; Nakano, O.; Barbin, D.; Villa Nova, N. 1976. Manual from Ecology of Insects = Manual de Ecologia dos Insetos. Editora Ceres, São Paulo, SP, Brazil (in Portuguese).

Storck, L.; Fiorin, R.A.; Cargnelutti Filho, A.; Guedes, J.V.C. 2012. A sampling procedure for quantifying mites in soybeans. Experimental \& Applied Acarology 57: 117-126.

Stürmer, G.R.; Cargnelutti Filho, A.; Stefanelo, L.S.; Guedes, J.V.C. 2012. Efficiency of sampling methods for caterpillars and stink bugs in soybean. Ciência Rural 42: 2105-2111 (in Portuguese, with abstract in English).

United States Department of Agriculture [USDA]. 2013. World agricultural production. Available at: http://www.fas.usda.gov/ psdonline/psdreport.spx?hidReportRetrievalName $=$ BVS\&hidR eportRetrievalID $=906 \&$ hidReportRetrievalTemplateID $=1$ [Accessed Apr 11, 2015]

Wade, M.R.; Scholz, B.D.G.; Lloyd, R.J.; Cleary, A.J.; Franzmann, B.A.; Zalucki, M.P. 2006. Temporal variation in arthropod sampling effectiveness: the case for using the beat sheet method in cotton. Entomologia Experimentalis et Applicata 120: 139-153. 